\title{
AN IMPROVED RESULT OF A WEIGHTED TRIGONOMETRIC INEQUALITY IN ACUTE TRIANGLES WITH APPLICATIONS
}

\author{
JIAN LIU
}

Abstract. An improved inequality of a weighted trigonometric inequality in acute triangles is established by using the simplest arithmetic-geometric mean inequality, which also is an improvement of the well known Wolstenholme inequality for non-obtuse triangles. Its two equivalent weighted inequalities for the strengthened versions of the Erdös-Mordell inequality and Barrow's inequality are obtained. Some applications are given by new results and five relevant interesting conjectures are also put forward.

Mathematics subject classification (2010): 51M16.

Keywords and phrases: Acute triangle, non-obtuse triangle, Wolstenholme inequality, Erdös-Mordell inequality, point.

\section{REFERENCES}

[1] O. Bottema, Geometric inequalities, Groningen: Wolters-Noordhoff, The Netherlands, 1969.

[2] T. O. Dao, T. D. Nguyen, N. M. Pham, A strengthened version of the Erdós-Mordell inequality, Forum Geom., 16(2016), 317-321.

[3] P. ERdös, Problem 3740, Amer.Math.Monthly., 42(1935), 396.

[4] T. HAYASHI, Two theorems on complex numbers, Tôhoku Math.J., 4(1913-1914),68-70.

[5] J. LiU, Three sine inequality, Harbin: Harbin institute of technology press, 2018.

[6] J. LiU, Several trigonometric inequalities for triangles (Chinese), Teaching Montyly., 11(1994), 1013.

[7] J. LIU, A Geometric inequality with one parameter for a point in the plane of a triangles, J. Math. Inequal., 8, 1(2014), 91-106.

[8] J. LIU, Sharpened versions of the Erdös-Mordell inequality, J. Inequal. Appl., 2015: 206(2015), 12.pp.

[9] J. LIU, Refinements of the Erdös-Mordell inequality, Barrow's inequality, and Oppenheim's inequality, J. Inequal. Appl., 2016: 9(2016), 18.pp.

[10] J. LiU, New refinements of the Erdös-Mordell inequality, J. Math. Inequal., 12, 1(2018), 63-75.

[11] D. S. Mitrinović, J. E. PeČarić, V. Volence. Recent Advances in Geometric Inequalities, Dordrecht-Boston-London: Kluwer Academic Publishers, 1989.

[12] B. Malesević, M.Petrović, B.Popkonstantinović, On the Extension of the Erdös-Mordell type inequalities, Math. Inequal. Appl.,17, 1(2014), 269-281.

[13] D. S. Marinescu, M. Monea, About a strengthened version of the Erdös-Mordell inequality, Forum Geom., 17(2017),197-202.

[14] A. Oppenheim, Problem E 1838, Amer.Math.Monthly., 72(1965), 1129.

[15] N. OzEKI, On P.Erdös' inequality for the triangle, J.College Arts Sci.Chiba Univ., 2(1957),247-250.

[16] A. W. Walker, Problem E 2388, Amer.Math.Monthly., 79(1935), 1135.

[17] J. Wolstenholme, A Book of Mathematical Problems, London-Cambridge, 1867. 